B6Exp1 CEA WGCNA-DS3 Multidimensional Scaling

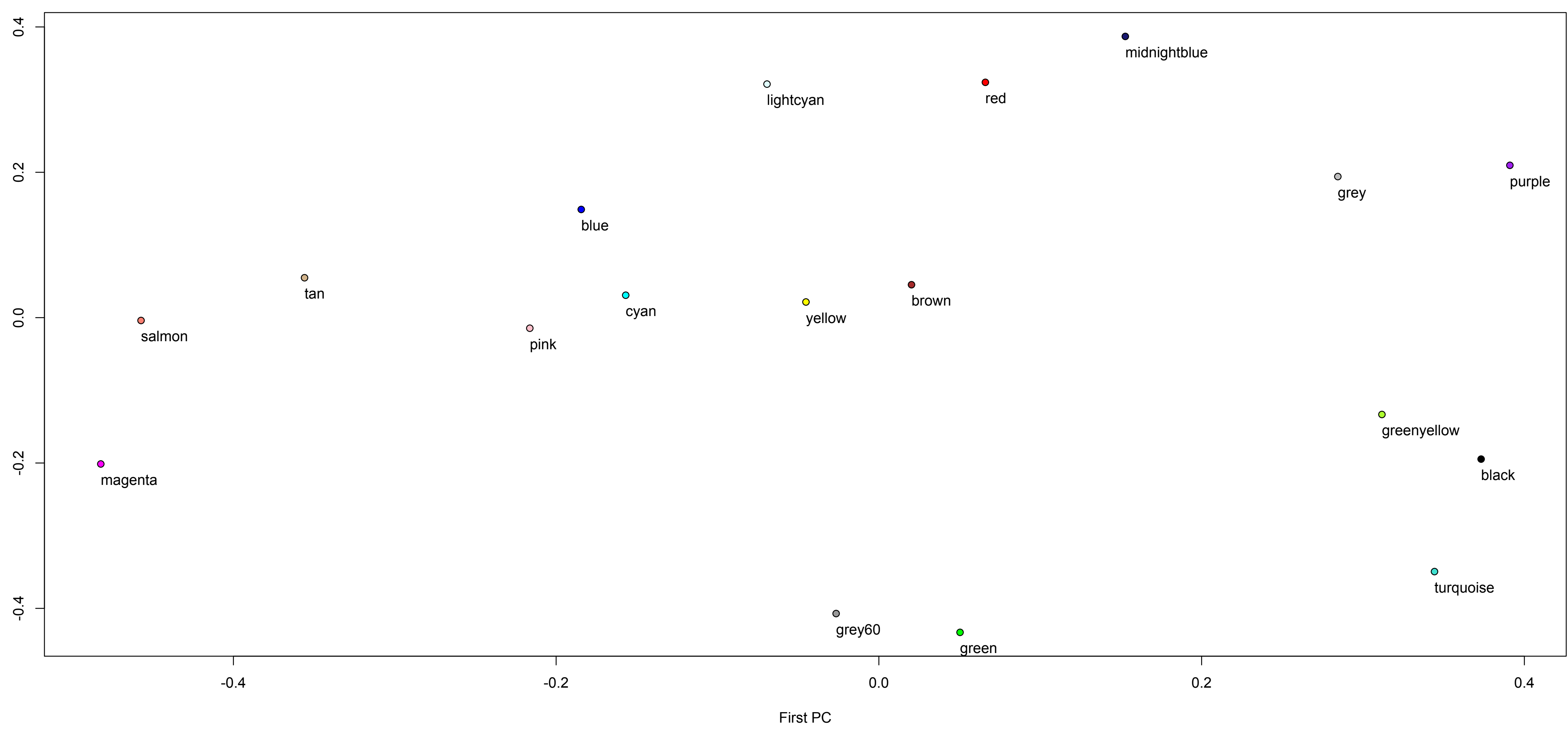




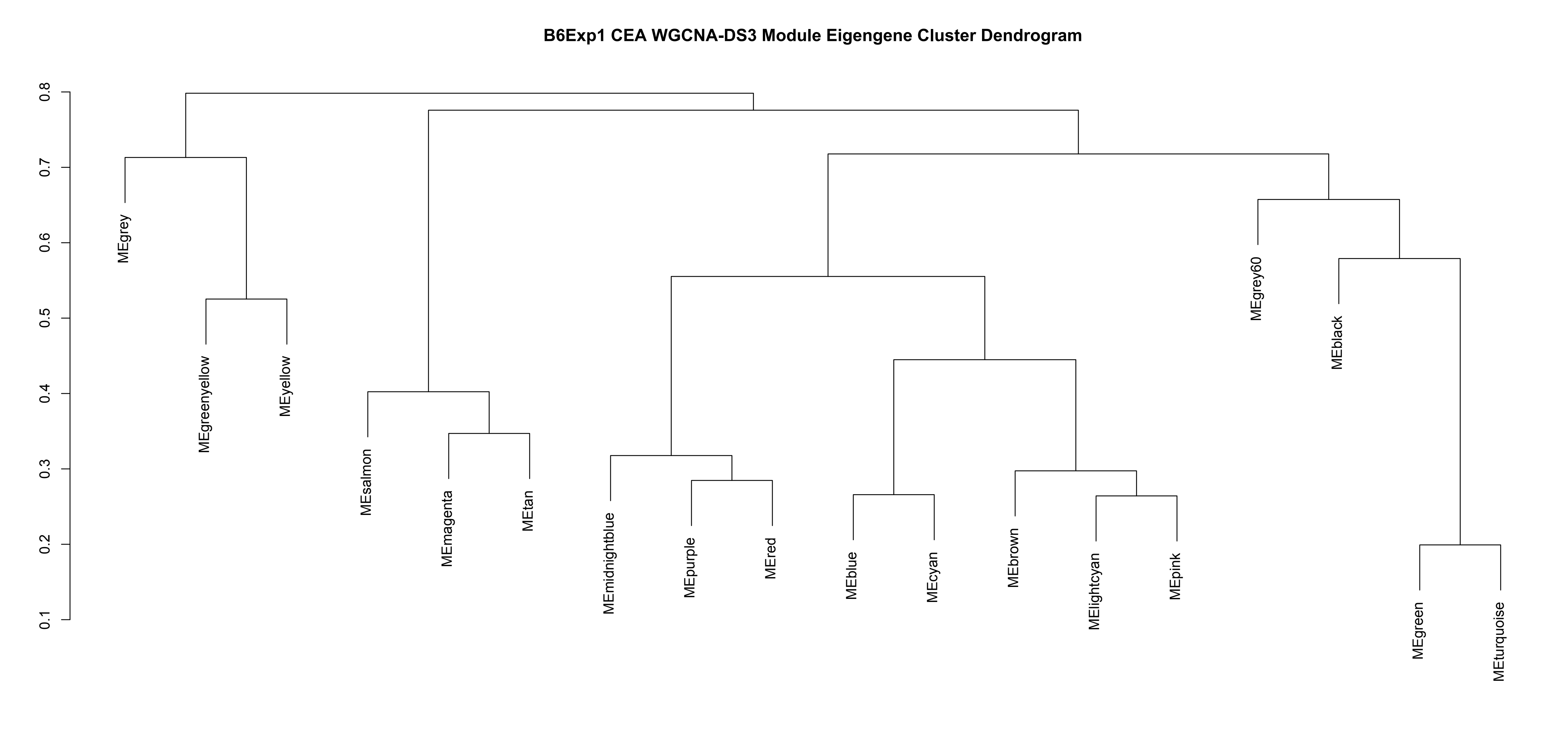




\section{CEA black}

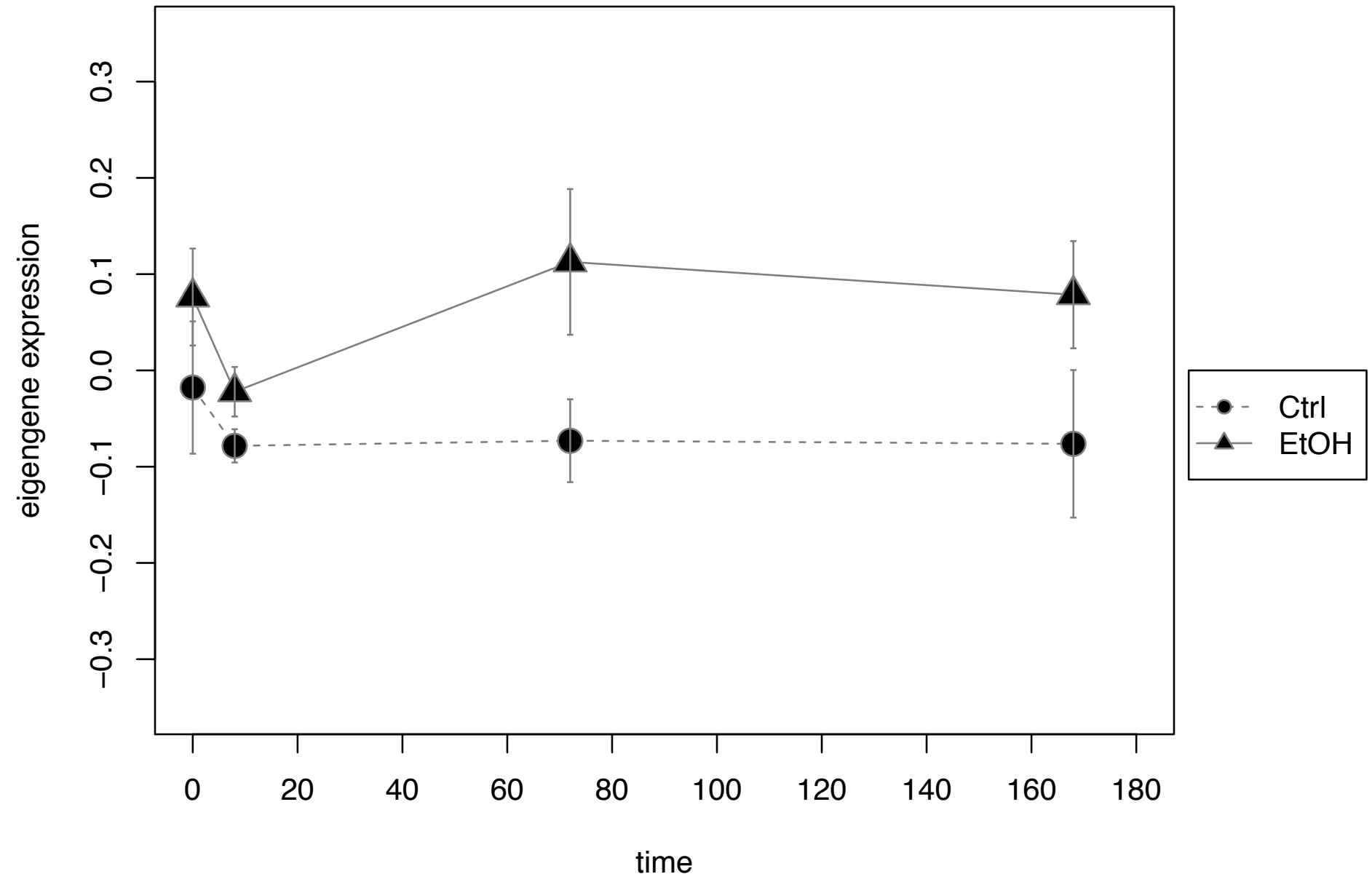




\section{CEA blue}

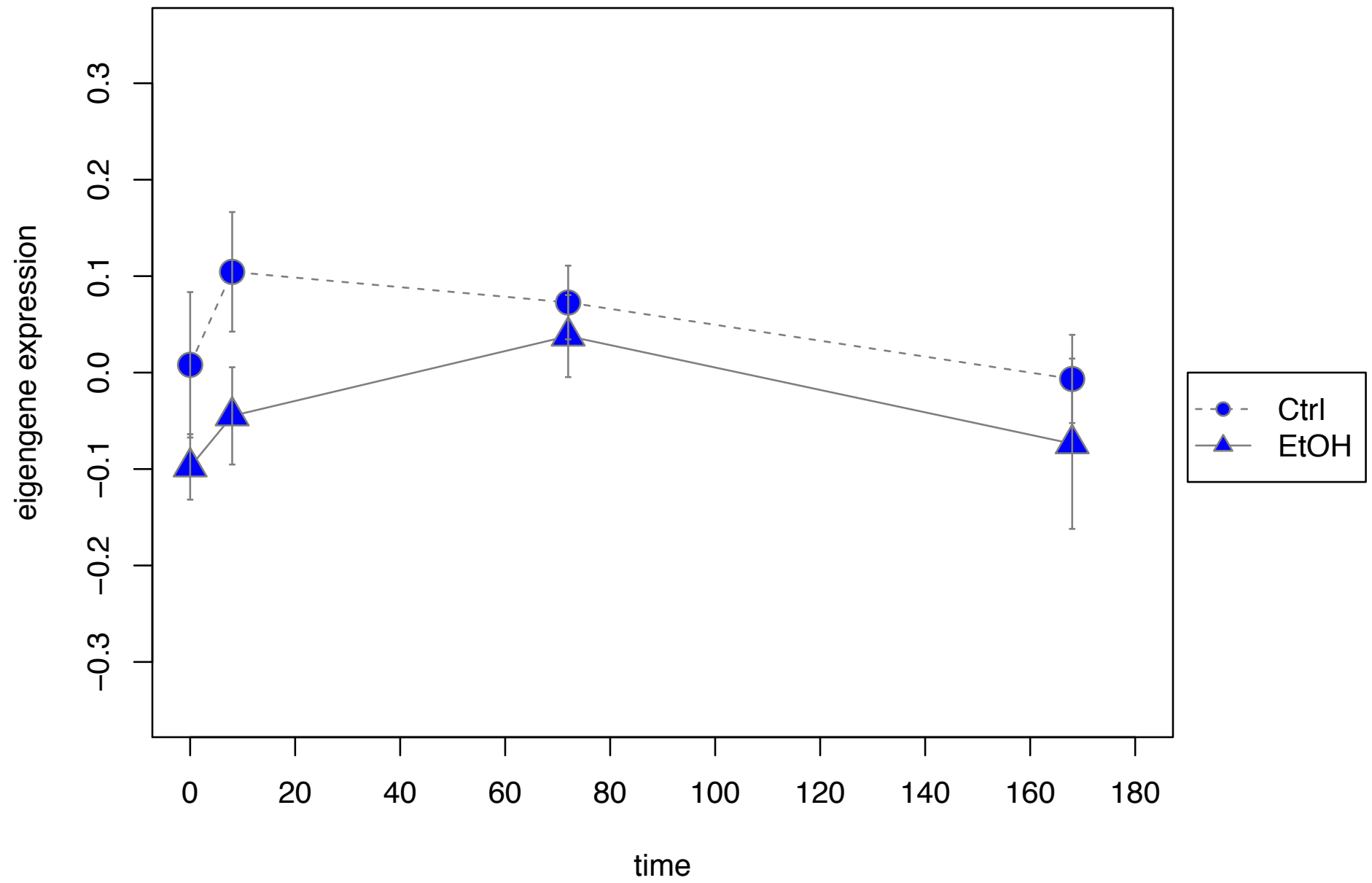




\section{CEA brown}

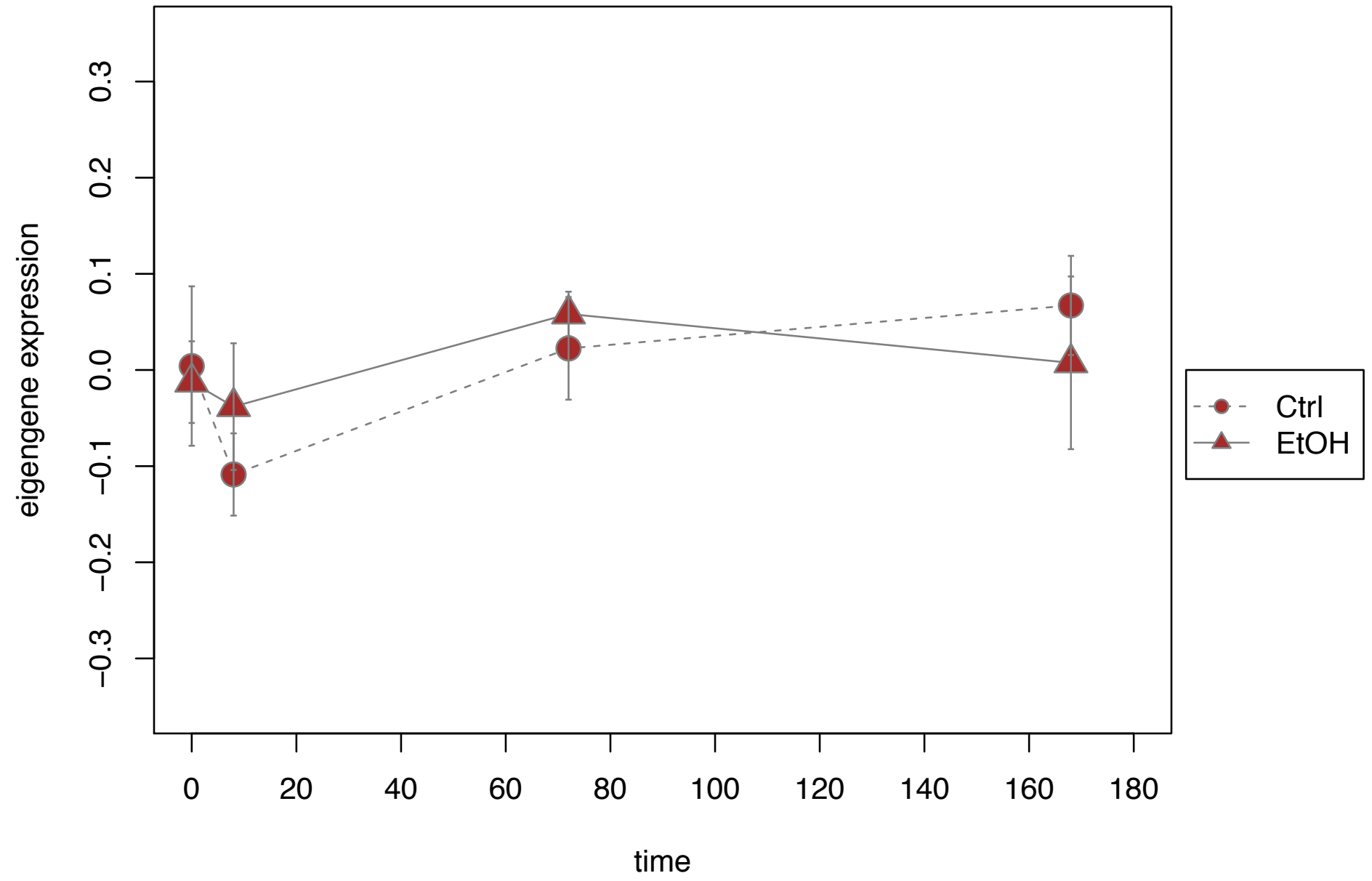




\section{CEA cyan}

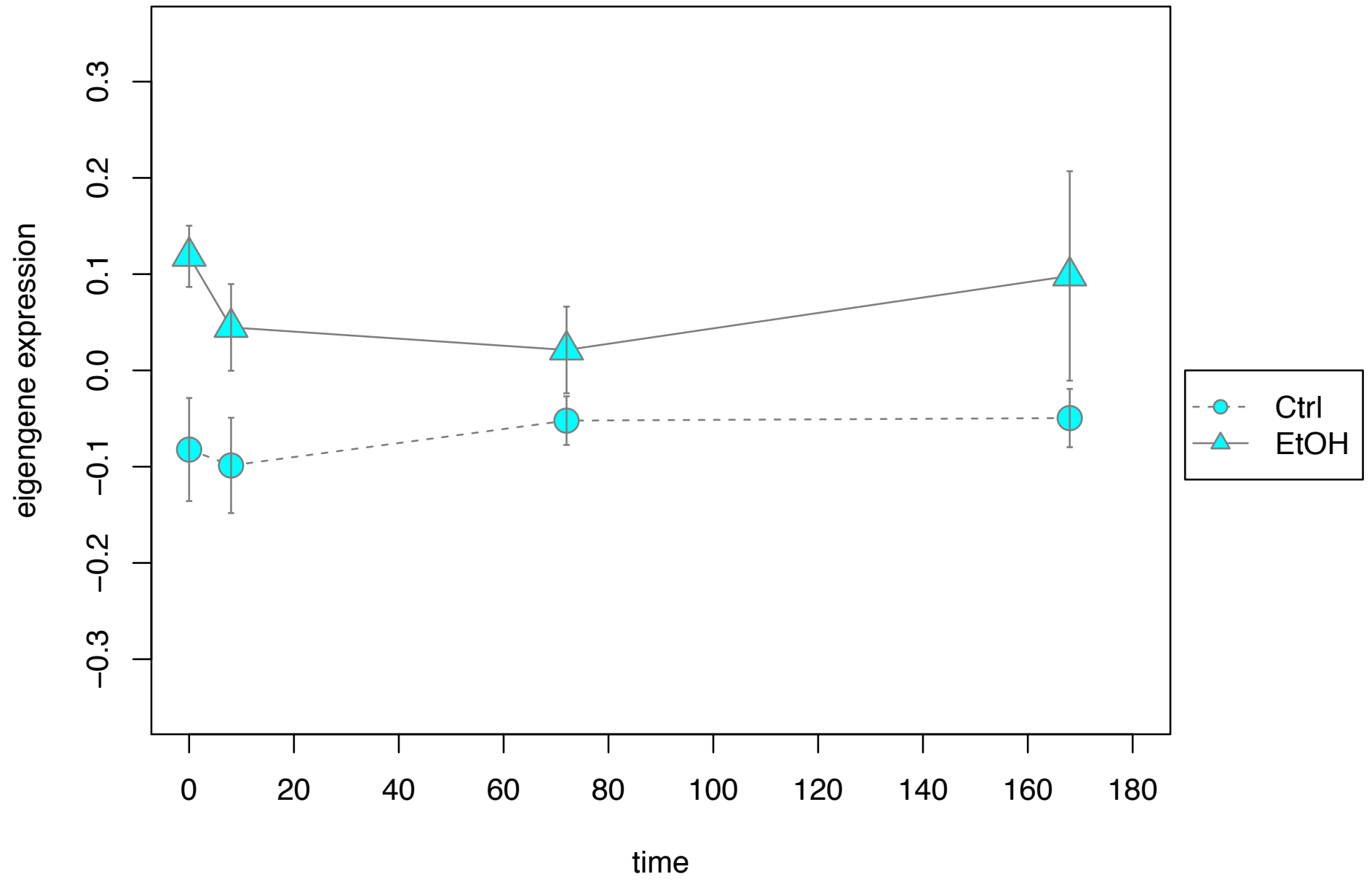




\section{CEA green}

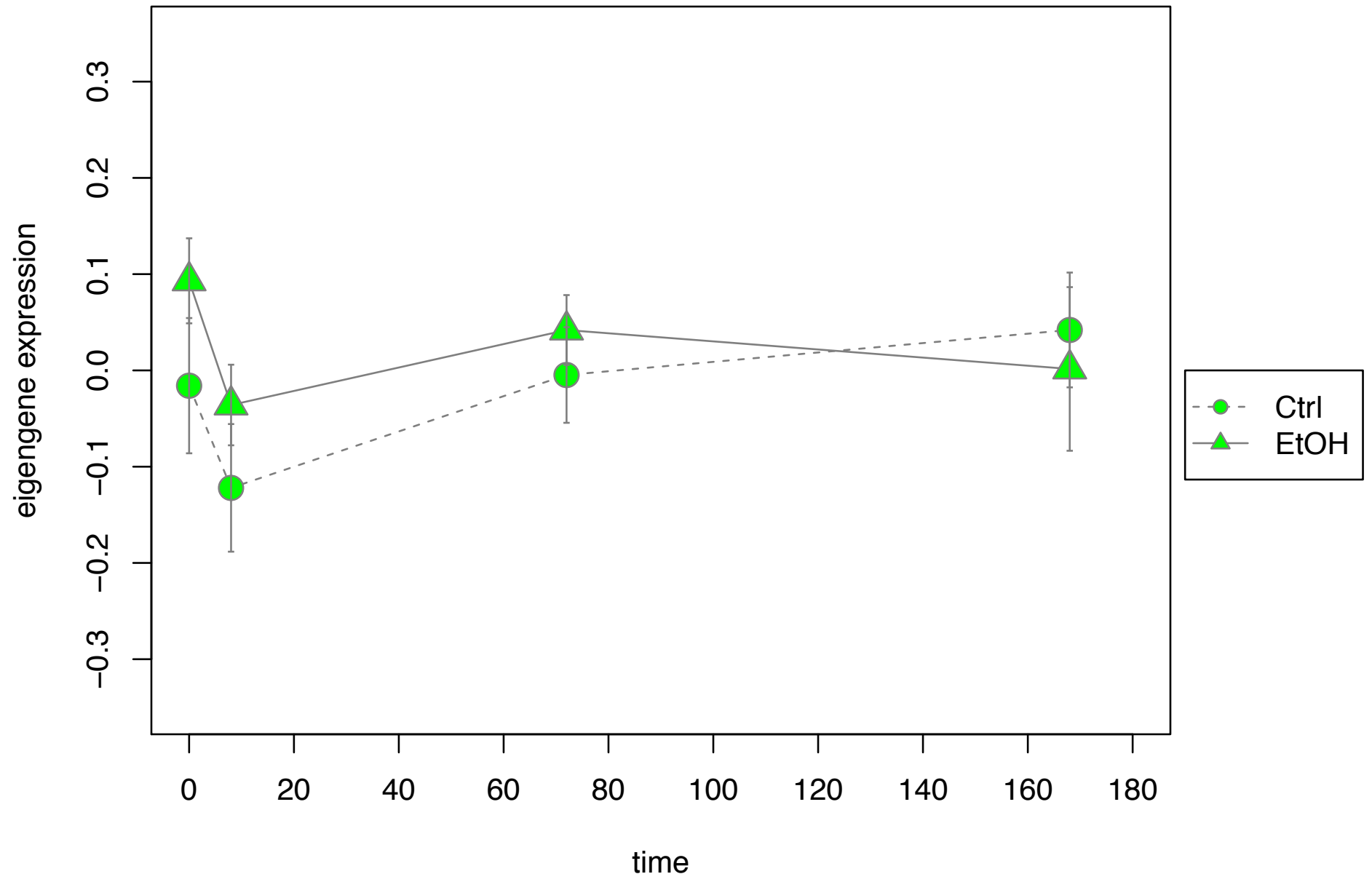




\section{CEA greenyellow}

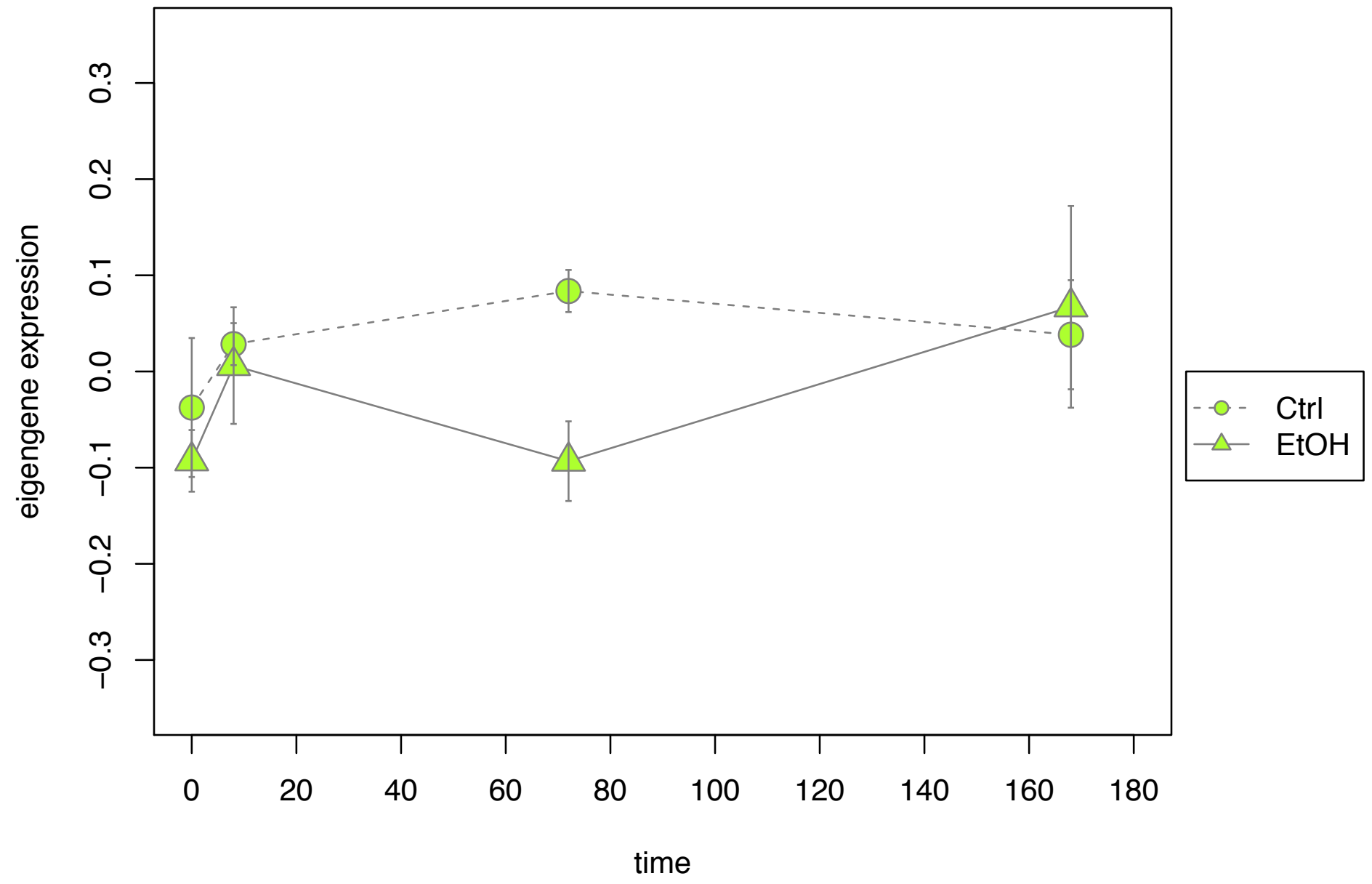




\section{CEA grey}

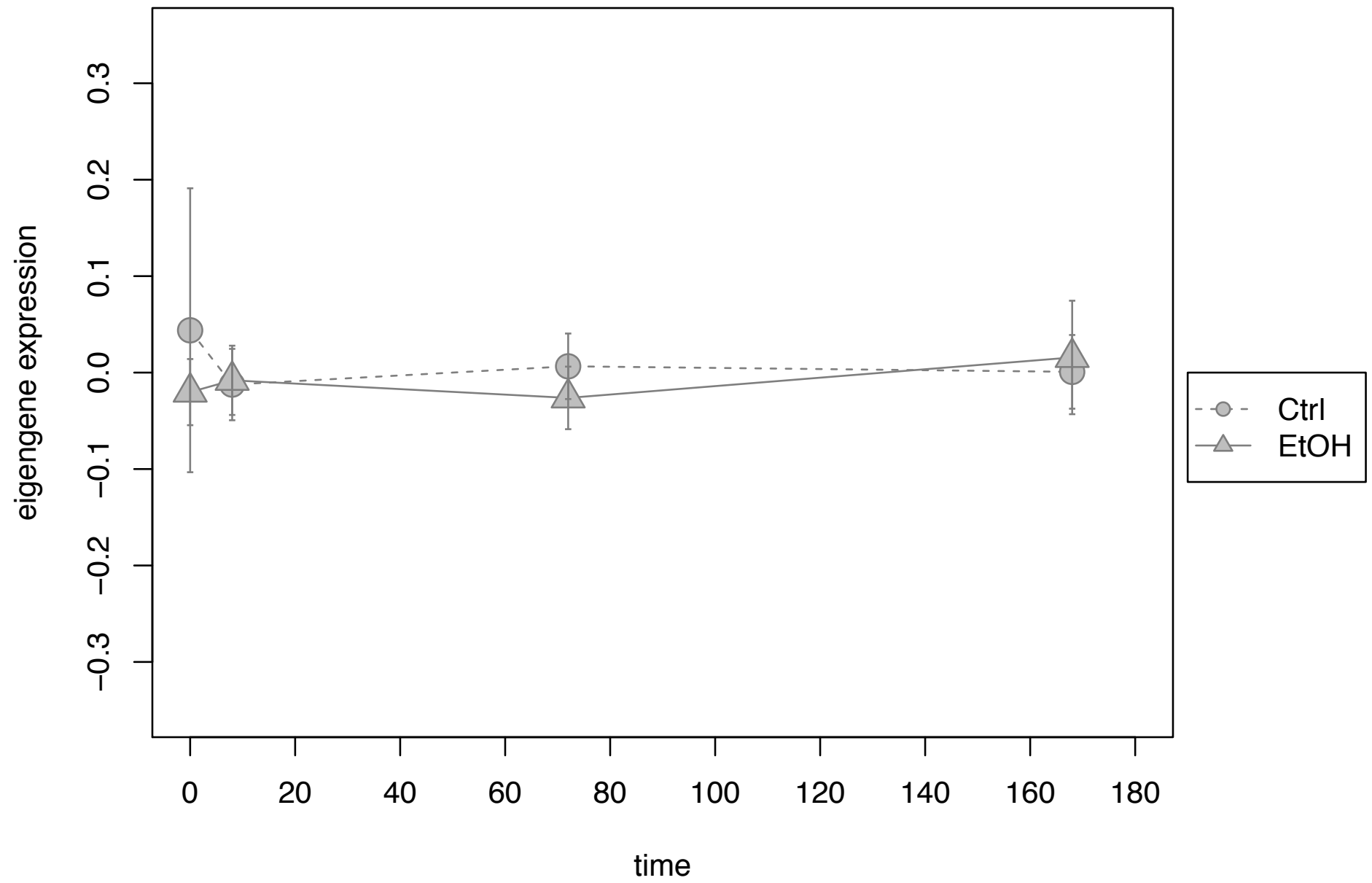




\section{CEA grey60}

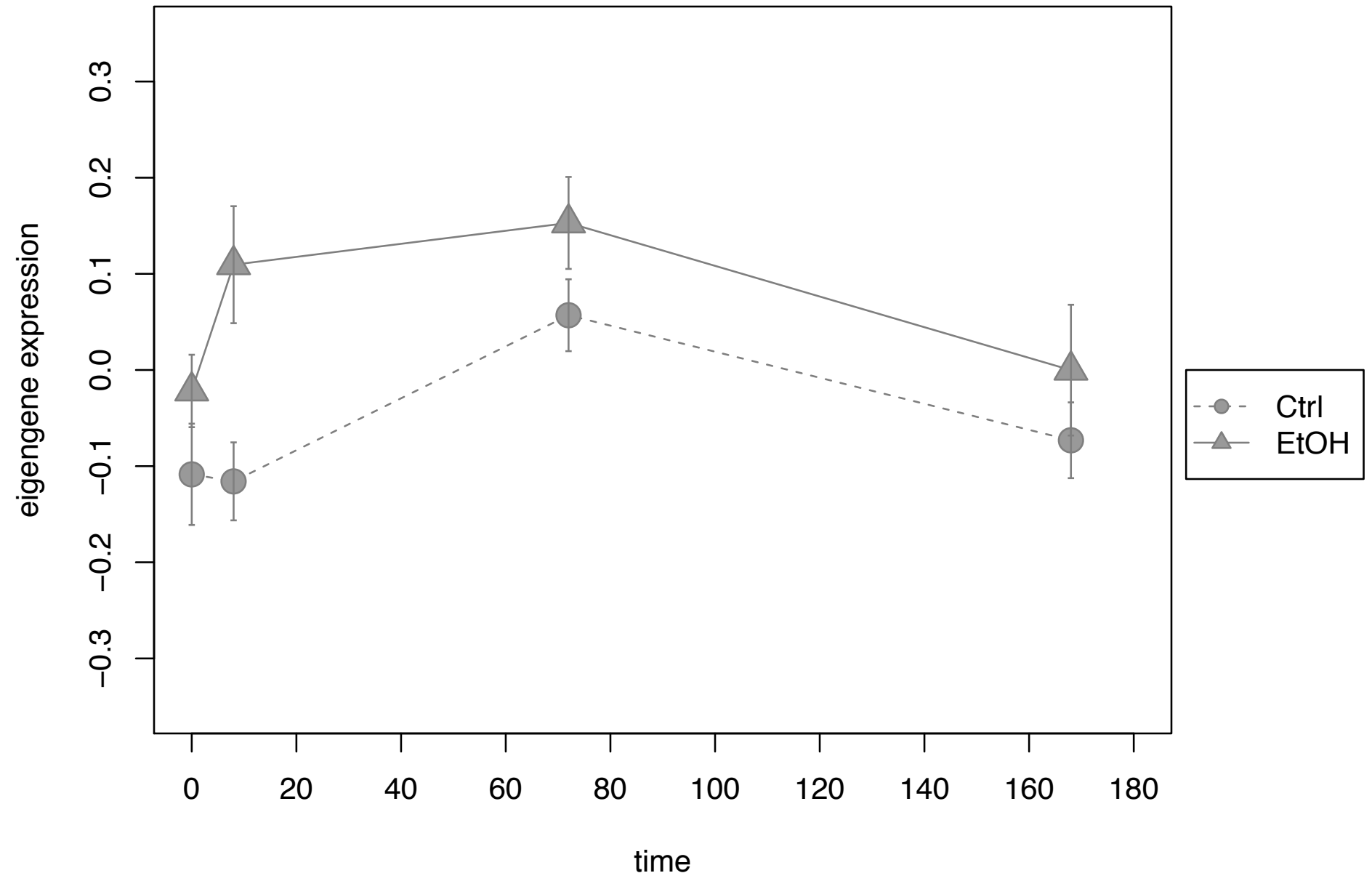




\section{CEA lightcyan}

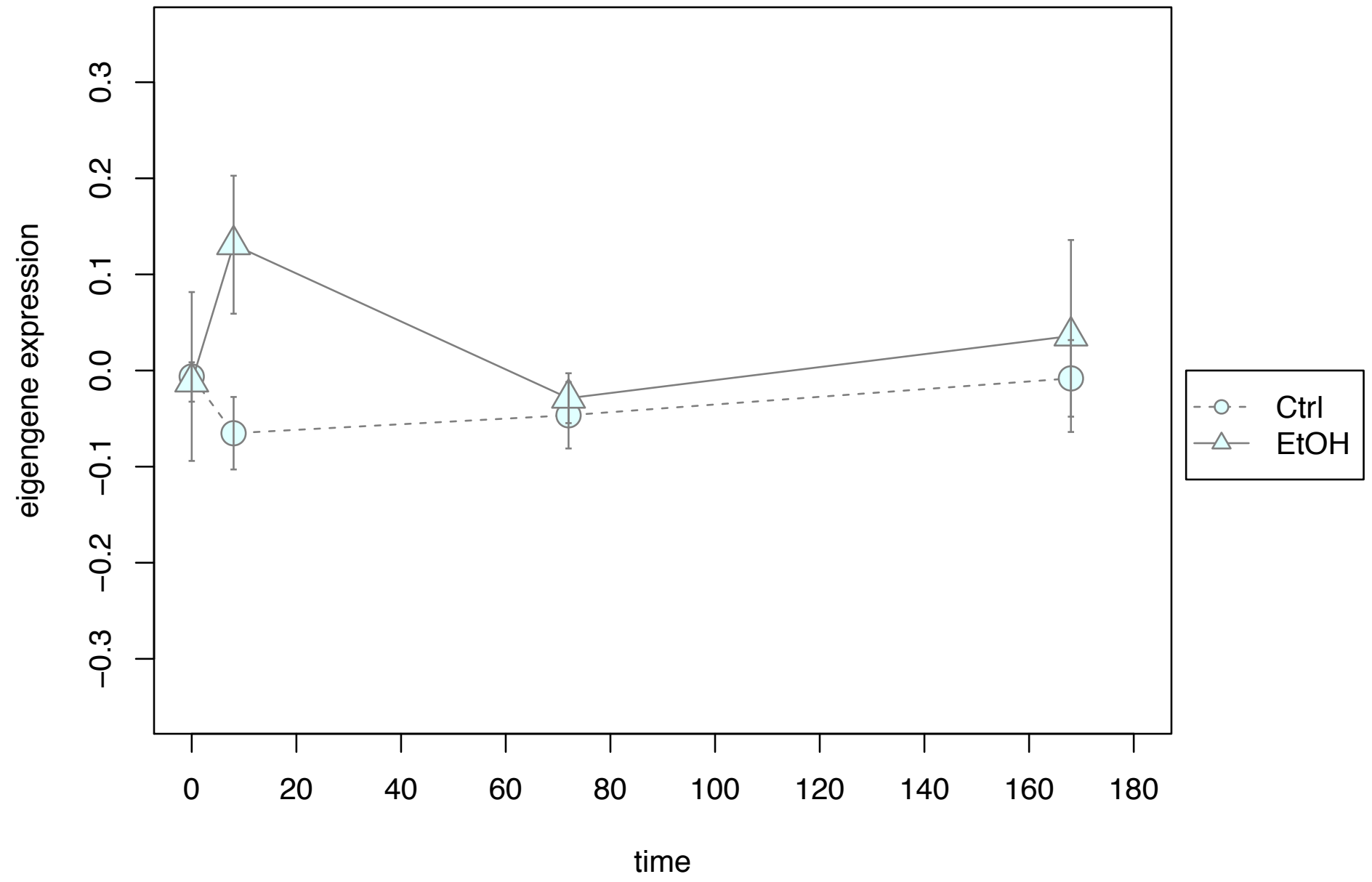




\section{CEA magenta}

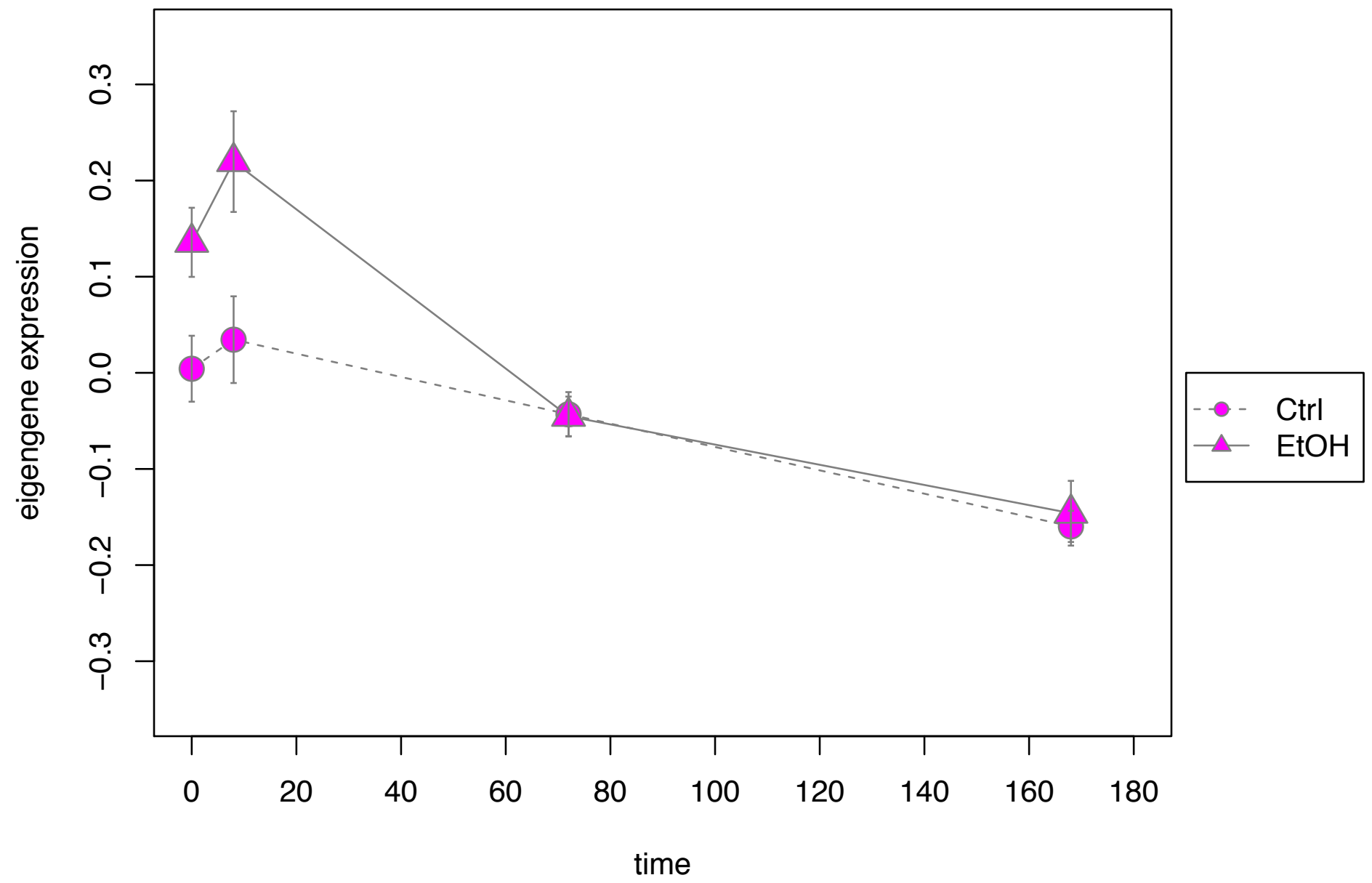




\section{CEA midnightblue}

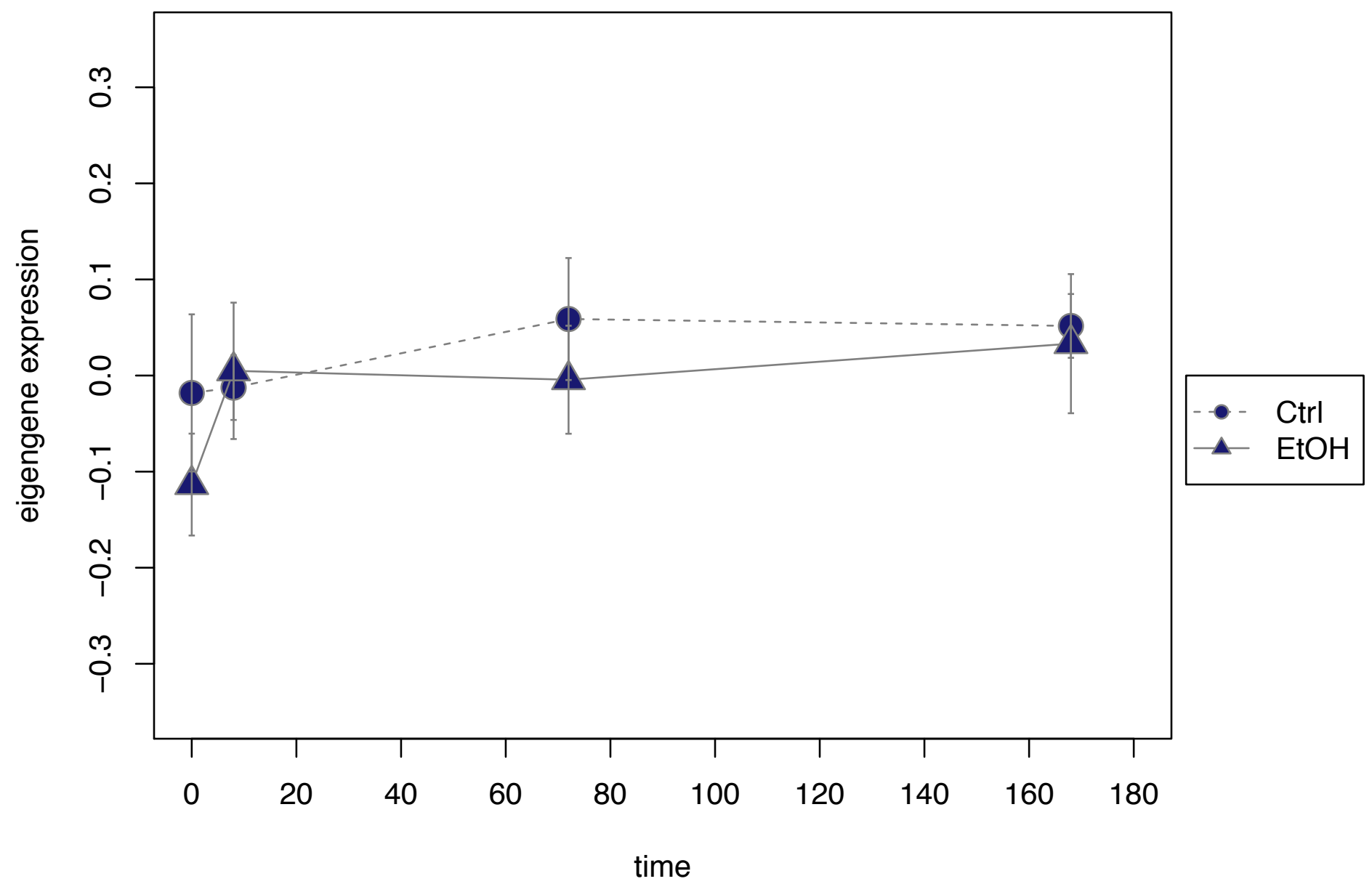




\section{CEA pink}

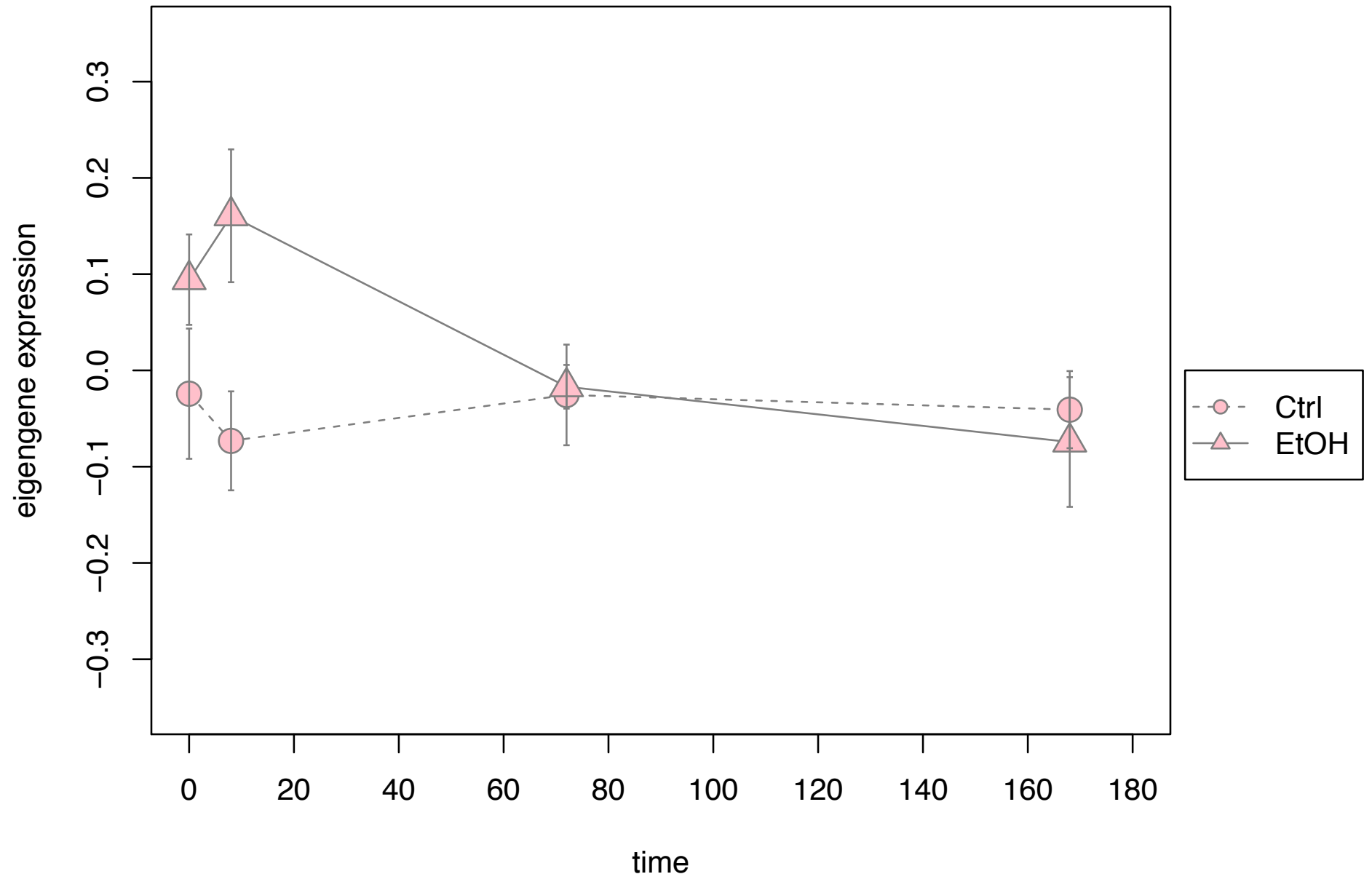




\section{CEA purple}

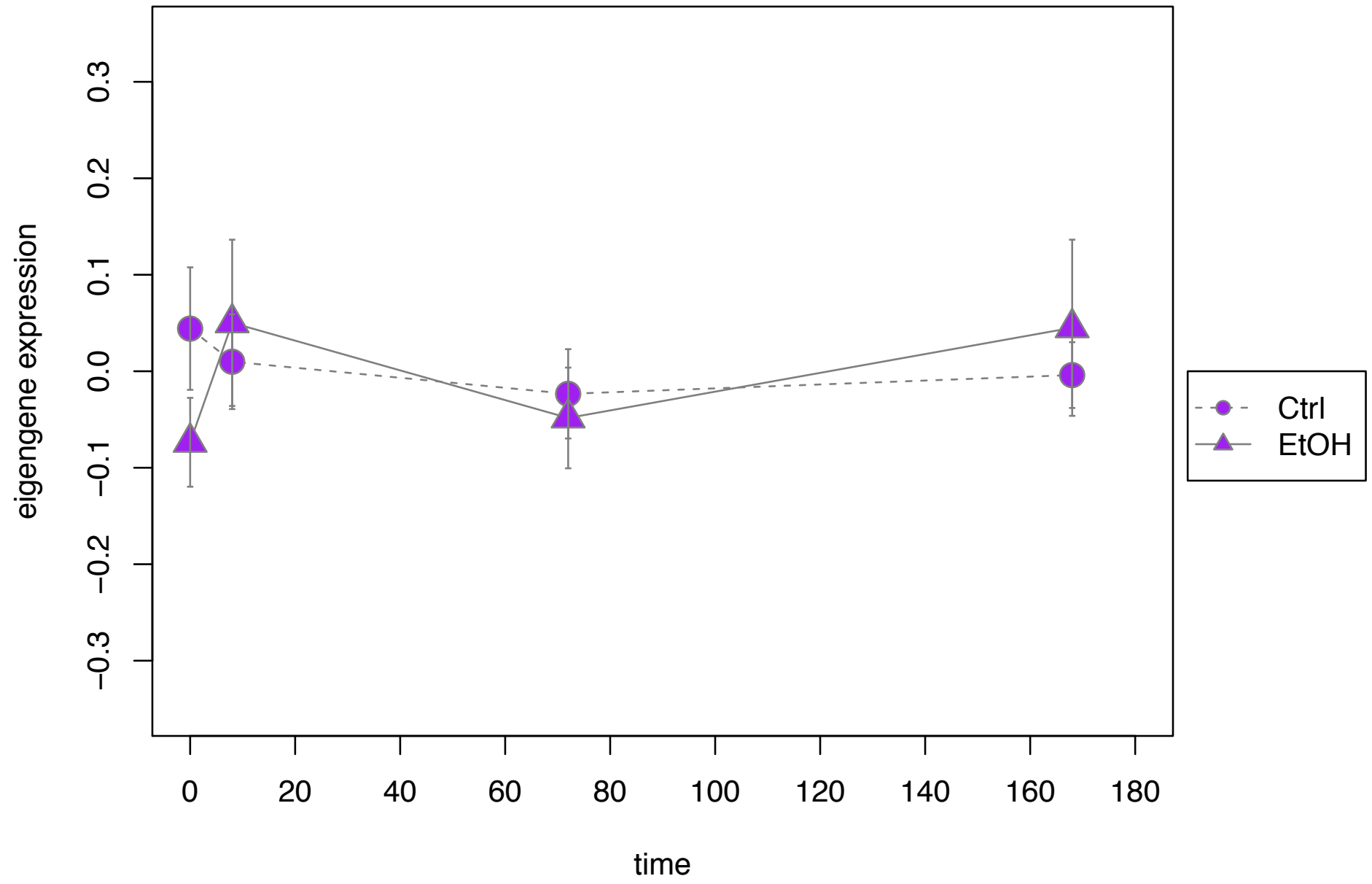


CEA red

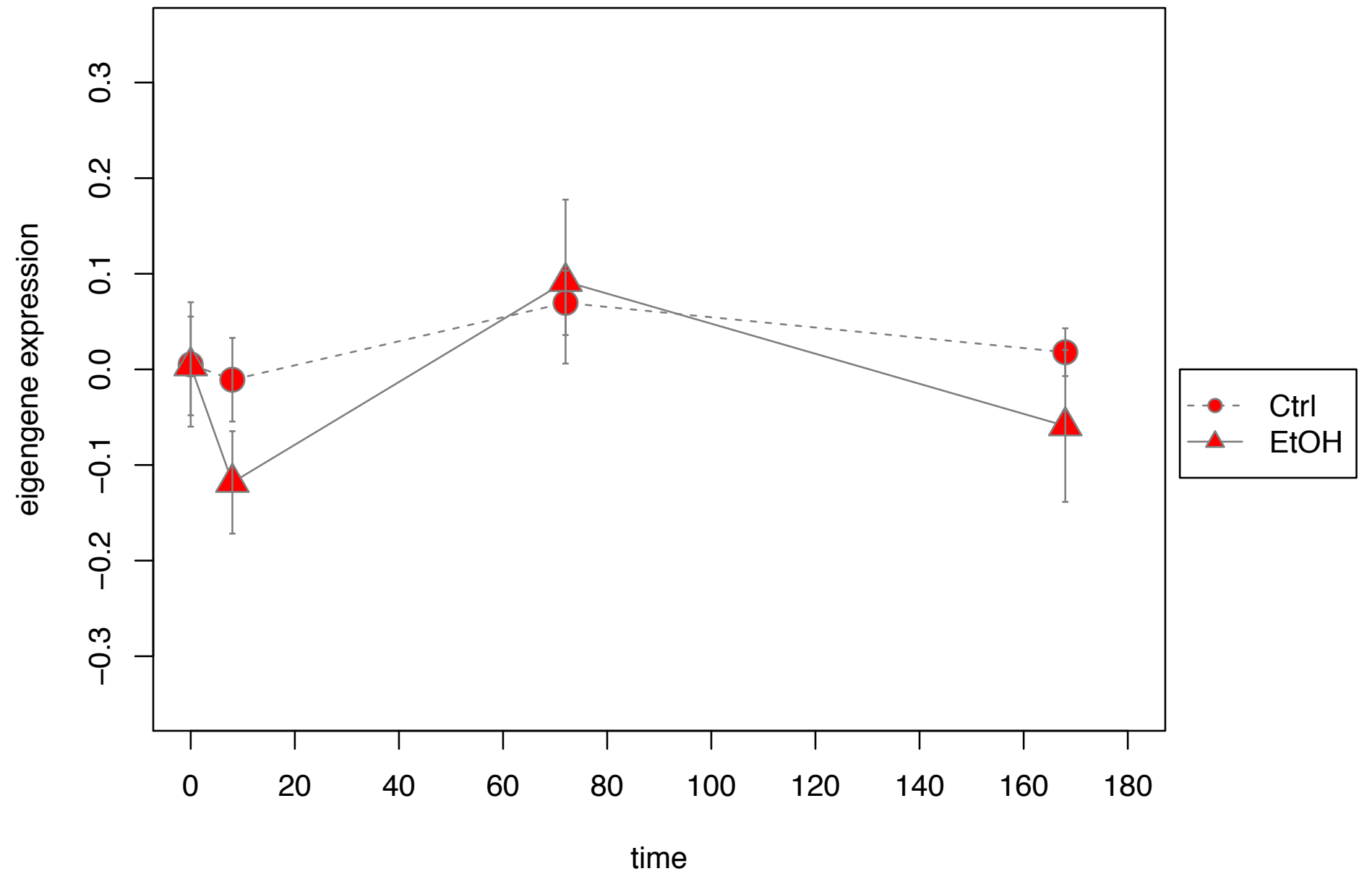




\section{CEA salmon}

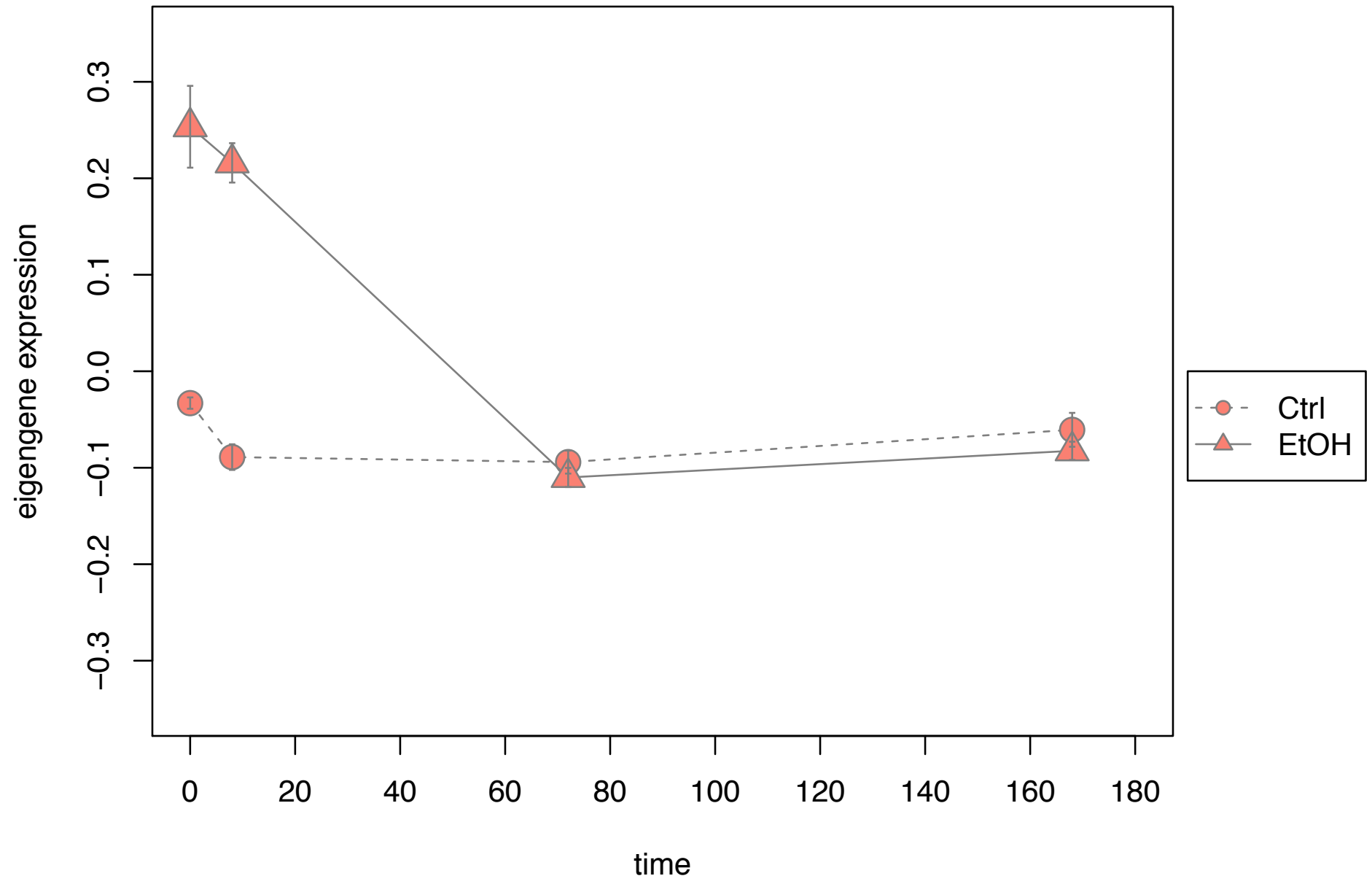


CEA tan

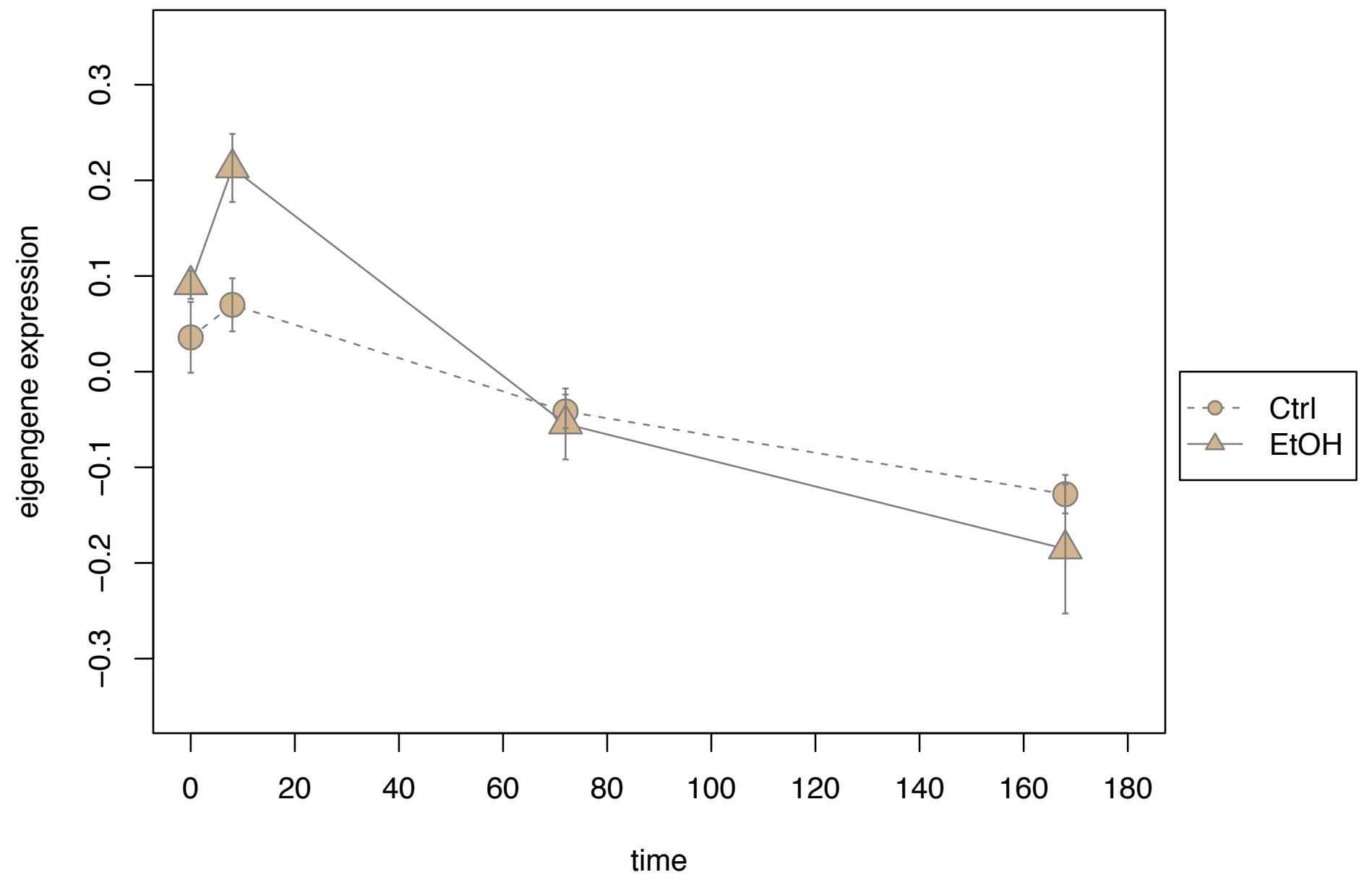




\section{CEA turquoise}

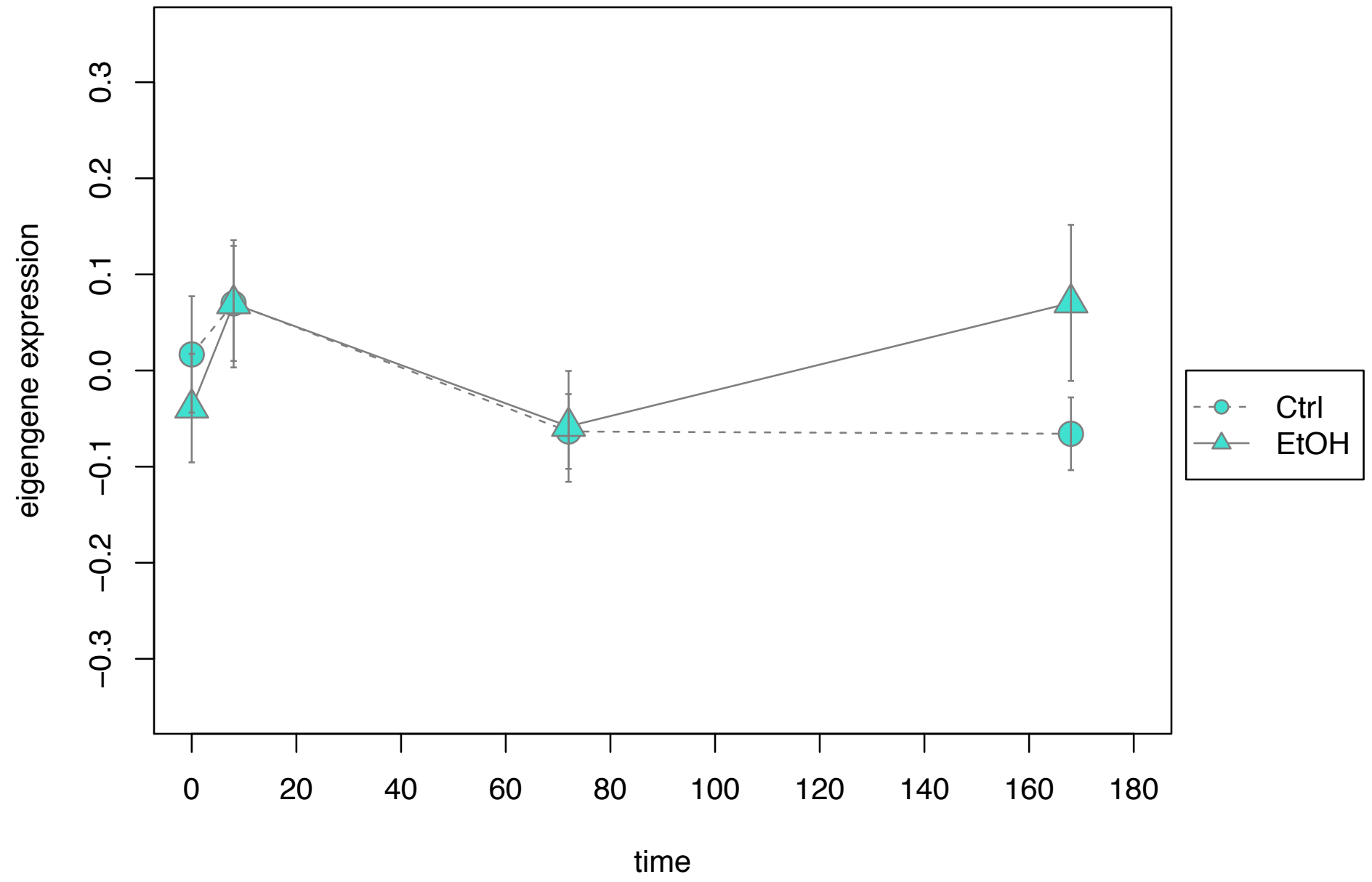




\section{CEA yellow}

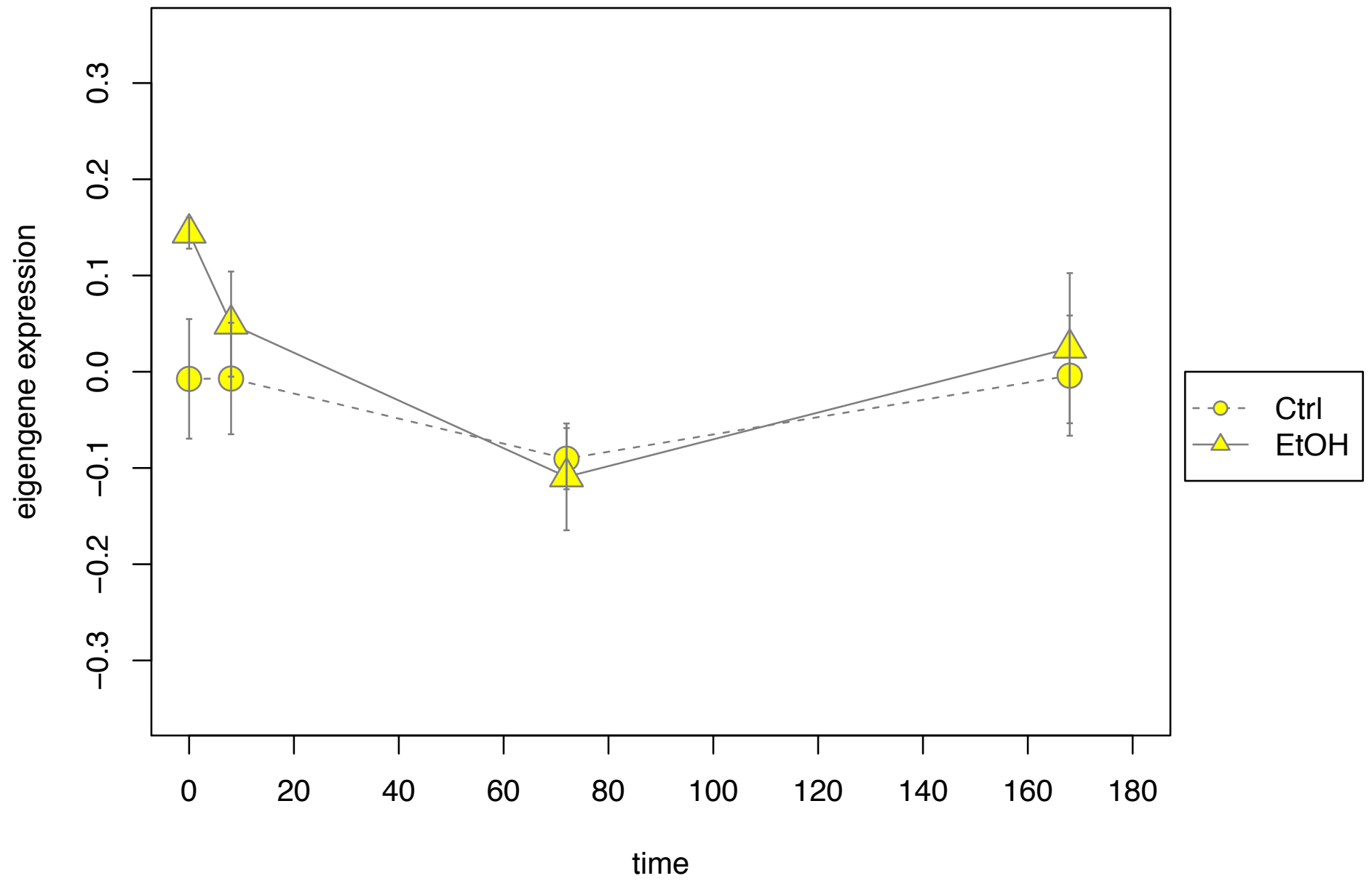

